PROBLEMS

OF EDUCATION

IN THE $21^{\text {st }}$ CENTURY

Volume 65,2015

\section{HOW TO CHOOSE THE RIGHT SUPERVISOR FOR THE PhD THESIS?}

\author{
Milan Kubiatko \\ Masaryk University in Brno, Czech Republic \\ E-mail: mkubiatko@gmail.com
}

I would like to thank the editor for the place and possibility to write a brief contribution to the problematic of supervisors. I know it is possible to write about this topic more than one page. Here, only a very short kind of information is presented toward this problem and maybe in the future, it will be possible to read more about this.

The right supervisor is one of the most important persons in the life of a $\mathrm{PhD}$ student. This cooperation aims to the quality of work (about the quality, I do not want to write, because this concept is very abstract and in the eyes of every person it means something else), next it influences the awareness, what the research work means. This relationship has an influence on the future life of students, as personal to work. We will be talking about the work life of the student. We can meet different types of supervisors, probably the worst one is the one, who has got students only for his own benefit (financial support - it depends on the country; the necessity for the next academic degree; publication purposes; students' work on the department; etc.). In this case students are dependent on their own skills and help from the others, except the supervisor. The supervisor is not able to help students, because the topic of the $\mathrm{PhD}$ thesis is out of the expertise of the supervisor. The supervisor has got many students and they are used only for technical works on the department and for the teaching process. In many cases, students teach instead of their supervisor. The professional life of students is very poor, their chance to develop skills and knowledge is very limited. They have not got a possibility to publish in prestigious journals, because they do not know about them and they finish after a certain time (time of the scholarship for study) without a PhD title. It is a great pity, because, certainly, there are very clever and skillful persons among these $\mathrm{PhD}$ students. In some cases, students belonging to this supervisor have got big luck and they meet the academician, whose help for the students is without any demand on the reward, but these situations are very rare.

The other type of supervisor is a better situation, but not ideal and, I think, it is relatively often. The supervisor has got time for the student and he is able to offer the advice to the student with his research work, but some worrisome things are still persistent. The student is still "slave" and makes many technical things, which are not in his competence. For example, he/ she is scanning, copying, and collecting material for the supervisor's teaching process or for his research activity. It is in normal conditions without time waste relatively ok, but if the student's research activity is threatened by these things, it is not right. In many cases, supervisors say "we also had to do these things". But it is not correct reasoning, if it is something bad, our task is to eliminate incorrect way of research. As it was written at the beginning of the paragraph, the supervisor has got the effort to help the students with their research activity, but this help is sometimes contra-productive. The supervisor is thinking "I know everything better than the student and he / she has to listen to me.". It is a little bit bad approach, students could read the sources, where there are more actual kinds of information. The truth is, the supervisor wants only the best thing regarding the research for the student, but the student is also a thinking personality with his own opinion. Nowadays, the research is aiming to the publishing in the journals, data based in WoS and SCOPUS. In the research world efforts are made about elimi- 
nating of publishing in non data based journals, because many scientific organizations doubt the process of publishing in this kind of journals. But many supervisors are editorial members

only of a local journal, where they have a possibility to make the publication process easier. So they aim the students to publish in this kind of journals without any effort to try to publish in data-based journals, where the reject rate also exists. The track of this supervisor on the student is very visible and in the future the supervisors will lead the students in the same way (publishing only in the local journals, an obligatory addition of the supervisor as co-author, too many teaching hours,...).

The last group of supervisors is very rare and endangered. They are also visionars, they have got a high level of creativity and they are very flexible and opened to new ideas. Their care about the students lies in the showing the correct aim of the research with the using of correct literary sources, with the potential to develop language skills of students. The supervisor uses the net of its contacts in home country and also in the foreign conditions. It allows to develop not only language skills, but also it increases the possibility to make students' research by correct way, where will be actual kinds of information and the research will be methodologically correct not only for local condition, but also for the whole research world. This kind of supervisor leads the students to the right publication activity in a data-based journal. This kind of student is ready for scientific world more in comparison with previous kinds of students. But there is a risk with the threat of the student, who is a product of a previous supervisor. So these students have got bigger problems with the finding a job in some university than the students from the previous supervisor. It is very interesting, because they bring more prestige and also kinds of support for the university. This is the situation mainly in post-communistic countries. I hope, that the situation will be changing very fast.

I know, the kinds of supervisors are different and there exist more kinds of supervisors than three as it was presented above. I wish all students only the best supervisors, so their work would be easy, productive with lots of success. 